\title{
Processing bodies require RNA for assembly and contain nontranslating mRNAs
}

\author{
DANIELA TEIXEIRA, UJWAL SHETH, MARCO A. VALENCIA-SANCHEZ, MURIEL BRENGUES, and ROY PARKER
}

Department of Molecular and Cellular Biology \& Howard Hughes Medical Institute, University of Arizona, Tucson, Arizona 85721-0106, USA

\begin{abstract}
Recent experiments have defined cytoplasmic foci, referred to as processing bodies (P-bodies), wherein mRNA decay factors are concentrated and where mRNA decay can occur. However, the physical nature of P-bodies, their relationship to translation, and possible roles of $\mathrm{P}$-bodies in cellular responses remain unclear. We describe four properties of yeast P-bodies that indicate that P-bodies are dynamic structures that contain nontranslating mRNAs and function during cellular responses to stress. First, in vivo and in vitro analysis indicates that P-bodies are dependent on RNA for their formation. Second, the number and size of P-bodies vary in response to glucose deprivation, osmotic stress, exposure to ultraviolet light, and the stage of cell growth. Third, P-bodies vary with the status of the cellular translation machinery. Inhibition of translation initiation by mutations, or cellular stress, results in increased P-bodies. In contrast, inhibition of translation elongation, thereby trapping the mRNA in polysomes, leads to dissociation of P-bodies. Fourth, multiple translation factors and ribosomal proteins are lacking from P-bodies. These results suggest additional biological roles of P-bodies in addition to being sites of mRNA degradation.
\end{abstract}

Keywords: decapping; P-bodies; stress; translation

\section{INTRODUCTION}

The regulation of mRNA turnover plays a significant role in controlling gene expression. In the last decade, specific pathways of mRNA turnover have been defined that can be controlled to modulate mRNA decay rates. In yeast, the major pathway of mRNA turnover is initiated with the shortening of the $3^{\prime}$ poly(adenosine) [poly(A)] tail, in a process referred to as deadenylation (for review, see Coller and Parker 2004). Shortening of the poly(A) tail leads to a deadenylated transcript that is primarily a substrate for removal of the $5^{\prime}$-cap structure by the Dcp1p/Dcp2p decapping complex, thereby exposing the transcript to degradation by the $5^{\prime}$-to- $3^{\prime}$ exonuclease, Xrn1p (Decker and Parker 1993; Hsu and Stevens 1993; Muhlrad and Parker 1994). Alternatively, transcripts can be degraded in a $3^{\prime}$-to- $5^{\prime}$ direction following deadenylation (Muhlrad et al. 1995; Mitchell et al. 1997; Jacobs et al. 1998). 3'-to-5' degradation is catalyzed by the exosome, a conserved complex of $3^{\prime}$-to$5^{\prime}$ exonucleases (for review, see van Hoof and Parker 1999).

Reprint requests to: Roy Parker, Department of Molecular and Cellular Biology \& Howard Hughes Medical Institute, University of Arizona, Tucson, AZ 85721-0106, USA; e-mail: rrparker@u.arizona.edu; fax: (520) 6214524.

Article published online ahead of print. Article and publication date are at http://www.rnajournal.org/cgi/doi/10.1261/rna.7258505.
Experiments in mammalian cells, and the conservation of the mRNA decay enzymes and factors, suggest that the major pathways are shared between yeast and mammals (for review, see Parker and Song 2004).

Decapping is a critical step in mRNA degradation because it both precedes and permits the degradation of the mRNA body. Several observations support the argument that the processes of mRNA decapping and translation are inversely related. First, mutations in different translation initiation factors that decrease translation rate also increase the rate of mRNA decapping (Schwartz and Parker 1999; Ramirez et al. 2002). Moreover, the cap-binding protein, which promotes translation initiation, is an effective inhibitor of decapping in vitro (Schwartz and Parker 2000; Ramirez et al. 2002; Khanna and Kiledjian 2004). Second, inhibition of translation initiation due to a strong secondary structure in the $5^{\prime}$-untranslated region (5'-UTR), or a poor AUG context, leads to faster decapping rates (Muhlrad et al. 1995; LaGrandeur and Parker 1999). Thus, decreasing translation initiation either in cis or in trans promotes faster decapping. Conversely, inhibition of translation elongation either by mutations or by treatment with elongation inhibitors (e.g., cycloheximide) leads to a decrease in the rate of decapping (Peltz et al. 1992; Beelman and Parker 1994). Similar experiments suggest translation and mRNA degradation are also related in mammalian cells (Muckenthaler et 
al. 1997). Together, these observations indicate that mRNA translation and mRNA decapping are in competition.

Insight into the competition between translation and decapping has come from recent experiments that identified discrete cytoplasmic foci in yeast and mammals, referred to as processing bodies (P-bodies). P-bodies include the decapping enzyme (Dcplp/Dcp2p), activators of decapping, Dhh1p (referred to as RCK in mammals), Pat1p, Lsm1-7p, Edc3p, and the 5'-3' exonuclease Xrn1p (Bashkirov et al. 1997; Ingelfinger et al. 2002; Lykke-Andersen 2002; van Dijk et al. 2002; Sheth and Parker 2003; Cougot et al. 2004; Kshirsagar and Parker 2004). P-bodies are suggested to be sites where decapping and degradation of mRNAs can occur. P-bodies size is proportional to the flux of mRNAs undergoing the decapping step in turnover, and mRNA decay intermediates trapped in the process of degradation are also localized to these structures in yeast (Sheth and Parker 2003). Similar observations were made in human cells, indicating that these cytoplasmic structures also represent sites of mRNA decay in more complex eukaryotes (Cougot et al. 2004). The conservation of P-bodies from yeast to mammals suggests that they play important roles in the cytoplasmic function of eukaryotic mRNAs including modulating their degradation.

The identification of P-bodies has led to a model wherein these structures represent pools of mRNAs that have exited translation and are destined for degradation (Sheth and Parker 2003). However, it is not known whether P-bodies are dependent on RNA for assembly or can form in an RNA-independent manner. Similarly, the hypothesized reciprocal relationship of $\mathrm{P}$-bodies and a translating pool of mRNA is largely based on the loss of P-bodies upon cycloheximide treatment (Sheth and Parker 2003; Cougot et al. 2004; Kshirsagar and Parker 2004). In this work we have addressed the role of RNA in P-body formation, the relationship of P-bodies to the translating pool of mRNA, and the variation in P-body size and number under a variety of conditions. The results suggest that P-bodies are dynamic and are affected by a range of cellular perturbations including glucose deprivation, osmotic stress, exposure to ultraviolet light, and the stage of cell growth. Moreover, our observations provide evidence that $\mathrm{P}$-bodies have a reciprocal relationship with translation and represent pools of nontranslating mRNPs. These results suggest a dramatic transition of mRNAs involving significant rearrangement of the mRNP for movement of mRNAs from the translating pool of mRNAs to P-bodies.

\section{RESULTS}

\section{P-bodies vary under different cellular conditions}

Initial studies of P-bodies suggested that there could be variation in the size and number of P-bodies depending on the experimental conditions (Sheth and Parker 2003). Thus, we examined how a variety of different growth and experimental conditions impact the number and size of yeast P-bodies using green fluorescent protein (GFP) tagged fusions of known P-body components (Sheth and Parker 2003). We primarily examined two proteins as P-body markers. First, we examined the distribution of Dcp $2 p$, which is a subunit of the decapping enzyme and is easily observed in P-bodies under all conditions. Second, we also examined the distribution of Dhh1p, which is an activator of the decapping reaction (Coller et al. 2001; Fischer and Weis 2002), which is weakly observed in P-bodies and generally more diffuse in the cytoplasm than Dcp2p. All pictures presented are collapsed stacks of a Z-series through yeast cells, unless stated otherwise. In addition, all observations described are seen in $>80 \%$ of the cells examined. The different conditions we examined and the results are discussed below.

\section{Stage of cellular growth affects P-body formation}

We examined how P-bodies vary during the stage of growth of a yeast culture, when provided glucose as a carbon source. Yeast cells in culture display a characteristic growth pattern in which a phase of logarithmic (log) growth is followed by a diauxic shift, a slow growth phase, and then by stationary phase. We observed that the size and number of P-bodies varied with the stage of growth. Furthermore, different P-body components have different dynamics in their association with P-bodies. Specifically, in cells in the early $\log$ phase of growth $\left(\mathrm{OD}_{600}=0.3\right)$, Dcp $2 \mathrm{p}$ is observed in multiple small P-bodies in the cell (Fig. 1A). In contrast, at this stage of growth, Dhhlp is generally diffuse, although some cytoplasmic foci can be observed (Fig. 1G). Moreover, examination of Dhhlp in a single Z-section from a series of confocal images reveals a clear concentration in P-bodies that is lost when a Z-series is collapsed (data not shown). The P-bodies seen in these experiments for Dcp2p and Dhhlp are smaller than has previously been described for yeast in mid-log growth (Sheth and Parker 2003). This difference is reconciled by the knowledge that the cells in the earlier publication were undergoing a partial stress response (see below).

As cell density increased and cells underwent diauxic shift, we observed an increase in brightness and number of P-bodies in cells, with clear and dramatic concentrations of Dcp2p and Dhh1p in foci (Fig. 1B-E,H-L). As cells reached even higher densities, $\mathrm{P}$-bodies continued to increase in size and the number per cell decreased (Fig. 1F,M). All known components of P-bodies examined (Patlp, Lsm1p, Dcplp, Xrn1p, Edc3p) show these changes in P-bodies with increasing cell density (data not shown). Thus, P-bodies increase in size and decrease in number with increasing cell density. The changes in P-body size roughly parallel changes in the use of different carbon sources during cell growth. However, P-bodies do not differ significantly when cells are grown in alternative carbon sources (data not shown). We 


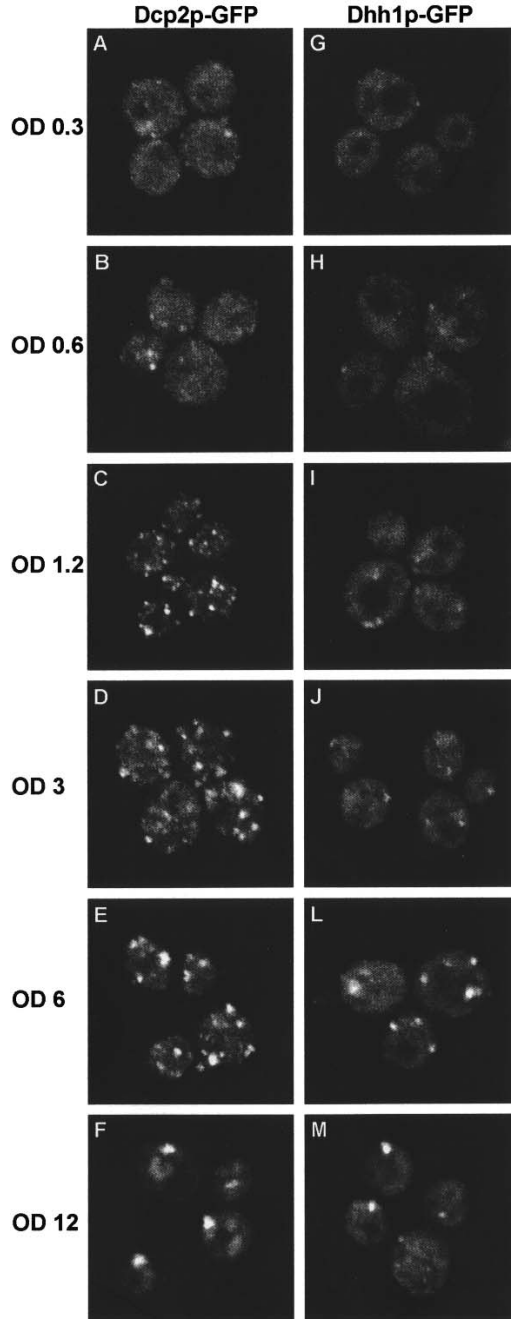

FIGURE 1. P-bodies increase with the stage of cell growth. Cells were grown in YPGlu and observed at different stages of cellular growth, as described. The different $\mathrm{OD}_{600}$ units (OD) are indicated at the left side of the figure. Cells expressing a GFP-tagged version of (left panel) Dcp2p (yRP1727) and (right panel) Dhh1p (yRP1724) are shown.

interpret these results to indicate that changes in cellular metabolism at different cell densities affect the flux of Pbody components in and out of P-bodies.

\section{P-bodies increase during glucose deprivation}

In order to examine how P-bodies respond to stress, we first examined how P-bodies changed with glucose depletion. Glucose is the preferred energy source for most eukaryotic cells, and yeast cells respond rapidly to glucose deprivation with changes in a wide variety of cellular processes (for review, see Rolland et al. 2002). We observed that when yeast cells were grown in rich medium containing glucose and shifted for 10 min to medium lacking glucose, P-bodies increased in brightness and number for both Dcp2p and Dhh1p (Fig. 2A, III, IV). This increase was not seen in cells shifted into fresh media containing glucose (data not

shown). Furthermore, we observed that Dhhlp foci colocalize with Dcp2p foci (Fig. 2B, III). Under these conditions, we observed the same increase in the concentration within P-bodies for Lsm1p, Pat1p, Edc3p, Dcp1p, and Xrnlp (data not shown). Interestingly, this increase in Pbodies inversely correlates with the rapid loss of translation induced by glucose deprivation (Ashe et al. 2000; Uesono et al. 2004), and suggests that inhibition of translation initiation leads to an increase in P-body formation (see below).

\section{P-bodies increase under osmotic stress}

We next examined the status of P-bodies in cells subject to osmotic stress. In yeast, changes in the extracellular osmolarity affect different signaling pathways (de Nadal et al. 2002), which can lead to a transient inhibition of protein synthesis (Uesono and Toh-e 2002). We first examined how early-log cells grown in glucose respond to hypotonic stress when exposed to water. We observed that induction of hypotonic shock by washing and incubating cells in either water or water supplemented with glucose for $10 \mathrm{~min}$ led to larger and more numerous P-bodies (Fig. 3A, III, IV; data not shown). In contrast, when cells were incubated in rich media and washed in synthetic media containing glucose,

A
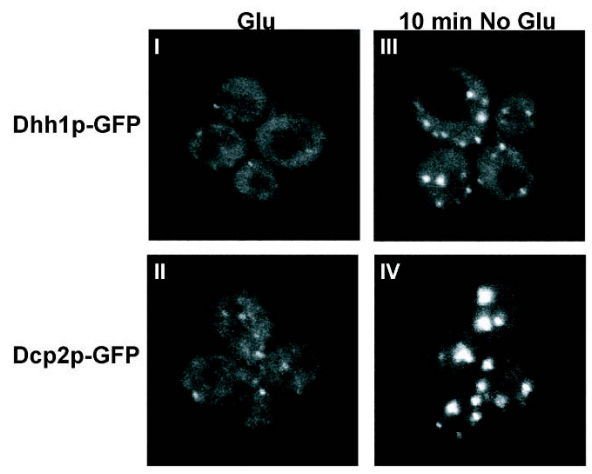

B
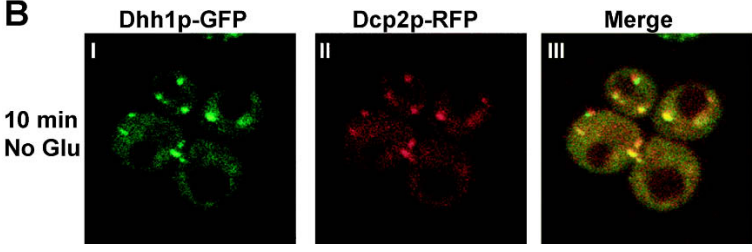

FIGURE 2. P-bodies size increases under glucose deprivation. $(A)$ Cells were grown in YPGlu, washed in YP, and resuspended in YP for $10 \mathrm{~min}$ before being collected. For observation, cells were washed with SC with $(I, I I)$ or without (III, IV) Glu, resuspended in the same SC, respectively, and observed. Cells expressing a GFP-tagged version of (top panel) Dhh1p (yRP1724) and (bottom panel) Dcp2p (yRP1727) are shown. (B) Cells were grown in SC plus Glu, washed, and resuspended in SC for 10 min before being collected. For observation, cells were washed and resuspended in SC without Glu. Cells coexpressing (I) a GFP-tagged version of Dhh1p (yRP1724) and (II) a RFP-tagged version of Dcp2p (pRP1186) are shown. (III) A merged view is shown. 
A
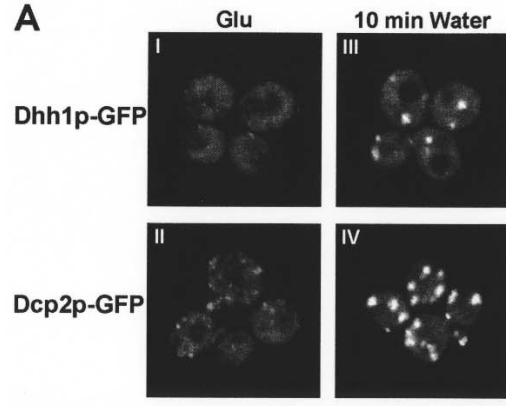

B

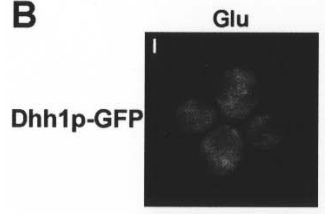

$15 \min 1 \mathrm{M} \mathrm{KCl}$
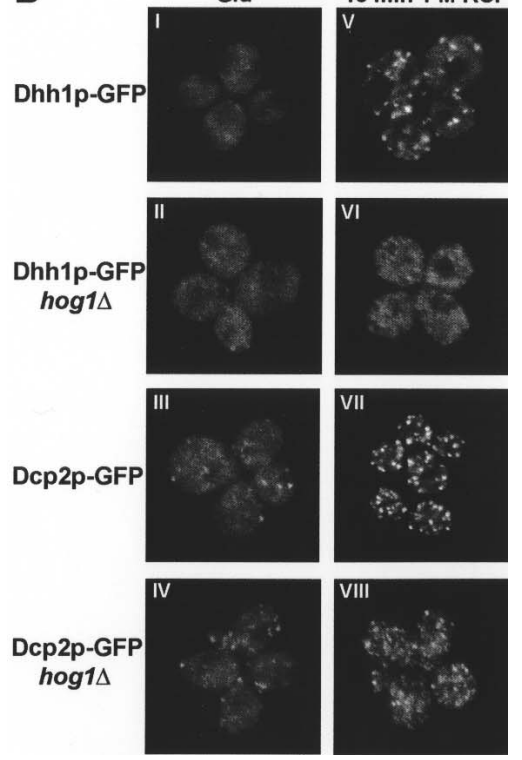

FIGURE 3. P-bodies are increased by osmotic stress. (A) The cells were grown in YPGlu, washed, and resuspended in water for $10 \mathrm{~min}$ before collection. For observation, cells were washed and resuspended in water $(I I I, I V)$. Cells expressing a GFP-tagged version of (top panel) Dhh1p (yRP1724) and (bottom panel) Dcp2p (yRP1727) are shown. (B) Cells expressing a GFP-tagged version of Dhhlp in a wild-type (yRP1724) or hog1s (yRP1912) strain (left panel), and Dcp2p in a wild-type (yRP1727) or hog1s (yRP1913) strain (right panel) after exposure to $1 \mathrm{M} \mathrm{KCl}$ for $15 \mathrm{~min}(V-V I I I)$ are shown. Cells were washed and resuspended in SC plus Glu supplemented or not with the same concentration of $\mathrm{KCl}$, and observed.

no changes in P-bodies were observed (data not shown). Similarly, P-bodies were examined under hyperosmotic stress conditions. After exposure of cells in the early-log stage of growth to either $1 \mathrm{M} \mathrm{KCl}$ (Fig. 3B, V, VII) or $0.8 \mathrm{M}$ $\mathrm{NaCl}$ (data not shown) for $15 \mathrm{~min}$, we observed a dramatic increase in P-body size and number, whether Dcp2p or Dhhlp was examined. Moreover, the increase in P-bodies in response to $1 \mathrm{M} \mathrm{KCl}$ was significantly reduced in a strain lacking Hoglp (Fig. 3B, VI, VIII), which is a critical kinase in the cellular response to osmotic stress (Uesono and Toh-e 2002). Consistent with a relationship between translation and P-body formation (see below), and the substantial but not complete reduction in P-body formation in hog1 $\Delta$ cells, we observed that cells lacking Hog1p also show a partial repression of translation in response to osmotic stress as judged by polysome profiles (data not shown). This suggests that the increase in P-bodies is influenced by the same signal transduction pathway that leads to other changes in cellular metabolism in response to osmotic stress. It should be noted that over time in wild-type cells, P-bodies returned to the status similar to that observed before the shift in osmolarity (data not shown). This transient nature suggests P-bodies may function in an aspect of the stress response (see Discussion).

\section{P-bodies are increased by exposure to ultraviolet light}

Yeast strains lacking the decapping regulators Lsm1p and Patlp are hypersensitive to ultraviolet (UV) light (Birrell et al. 2001). We therefore examined the status of P-bodies in yeast cells exposed to UV light. We observed that the concentrations of Dhh1p and Dcp2p increased in P-bodies following exposure to UV (Fig. 4C,E,G, 4D,F,H). This observation coupled with the UV hypersensitivity of the $l s m 1 \Delta$ and pat $1 \Delta$ strains suggest that $\mathrm{P}$-bodies may have a function in the cellular response to UV damage.

\section{P-bodies and translation show a reciprocal relationship}

The above results indicate that the number and size of P-bodies in the cell increase in response to several cellular stresses and growth limitations. Because many of these conditions affect translation, a likely hypothesis is that mRNAs undergoing translation are excluded from P-bodies, while nontranslating mRNAs can assemble into P-bodies. In order to test this hypothesis, we examined the size and number of P-bodies when translation is directly altered.

\section{P-bodies are affected by translation initiation rates}

In order to analyze the effect of defects in translation initiation, we examined P-bodies using a strain carrying a conditional temperature-sensitive allele (prt1-63) of the

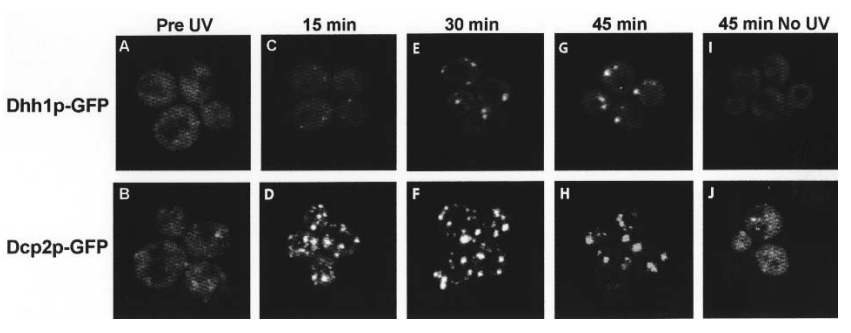

FIGURE 4. P-bodies are increased by exposure to UV light. Localization of GFP-tagged (top panel) Dhhlp (yRP1724) and (bottom panel) Dcp2p (yRP1727). Cells $(A, B)$ before UV treatment and $(C, D)$ $15 \mathrm{~min},(E, F) 30 \mathrm{~min}$, and $(G, H) 45 \mathrm{~min}$ after UV treatment. $(I, J)$ Localization of unexposed cells treated the same way as UV-treated cells. 
translation initiation factor Prt1p, which is a subunit of the eIF3 complex. In the prt1-63 strain, translation is inhibited at the nonpermissive temperature of $37^{\circ} \mathrm{C}$ (Evans et al. 1995). We observed that following $20 \mathrm{~min}$ at $37^{\circ} \mathrm{C}$, P-bodies increased in size in the prt1-63 strain (Fig. $5 \mathrm{~A}, \mathrm{IV}, \mathrm{VIII})$. Similarly, when we shifted for $20 \mathrm{~min}$ to $37^{\circ} \mathrm{C}$ a strain carrying a conditional temperature-sensitive allele of the translation initiation factor eIF4E, we observed an increase in P-body size (data not shown). No effect was seen when a wild-type strain was shifted to $37^{\circ} \mathrm{C}$ for $20 \mathrm{~min}$ (Fig. 5A, III, VII). These results indicate that P-bodies increase as a consequence of defects in translation initiation.

Inhibition of translation elongation leads to dissociation of all known components of P-bodies

The increase in P-bodies when translation initiation is inhibited suggests that P-bodies are forming on a pool of nontranslating mRNPs. Consistent with that result, the presence of Dhhlp and Edc3p in P-bodies is abolished when cells are treated with cycloheximide, which is an inhibitor of translation elongation and leads to mRNA accumulation on polysomes (Sheth and Parker 2003; Kshirsagar and Parker 2004). These findings suggest that either P-bodies themselves dissociate when mRNAs are trapped in polysomes, or that Dhhlp and Edc3p require ongoing translation for their localization in P-bodies. In order to distinguish these two possibilities, we examined the distribution of all known P-body components in response to cycloheximide treatment.

We first examined the effect of cycloheximide on P-bodies under conditions of osmotic stress, where P-bodies are large and numerous. Cells were washed and resuspended in water with, or without, cycloheximide. Every known component of P-bodies was no longer observed in foci following a 10-min treatment with $100 \mu \mathrm{g} / \mathrm{mL}$ of cycloheximide (Fig. 5B, IV-VI, X-XII). Although these results were obtained under osmotic stress conditions, similar results are seen
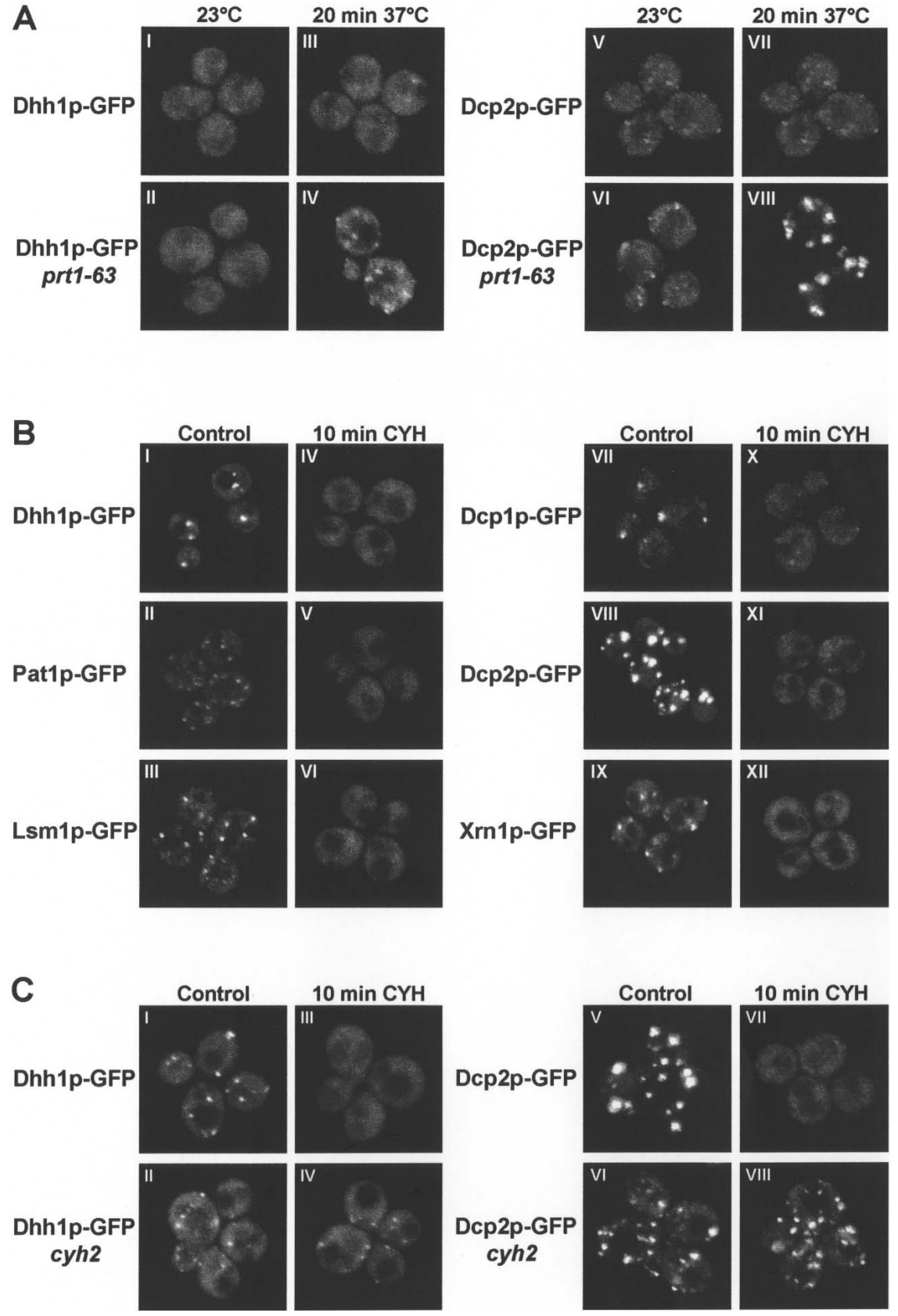

FIGURE 5. (A) P-bodies are affected by translation initiation rates. Cells expressing a GFPtagged version of Dhhlp carrying the conditional ts allele prt1-63 (yRP1826) or a wild-type allele (yRP1724) and cells expressing a GFP-tagged version of Dcp2p carrying the conditional ts allele prt1-63 (yRP1827) or a wild-type allele (yRP1727) were grown in YPGlu at $23^{\circ} \mathrm{C}$ $(I, I I, V, V I)$ and then shifted to $37^{\circ} \mathrm{C}$ for $20 \mathrm{~min}(I I I, I V, V I I, V I I I)$. Cells were collected, washed, and resuspended in SC with Glu; cells were kept at $37^{\circ} \mathrm{C}$ for observation. (B) Inhibition of translation elongation disrupts P-bodies. Cells were grown in YPGlu. The culture was divided into two samples; cycloheximide (CYH) at a concentration of $100 \mu \mathrm{g} / \mathrm{mL}$ was added to one sample. The cells were grown for another $10 \mathrm{~min}$ before they were collected. The water used for washing and resuspension of the cycloheximide-treated cells contained the same concentration of the drug $(I V-V I, X-X I I)$. The other sample was treated similarly but without adding the drug (I-III,VII-IX). Dcplp (yRP1726), Dcp2p (yRP1727), Dhh1p (yRP1724), Lsm1p (yRP1729), Patlp (yRP1728), and Xrn1p (yRP1730) GFP-tagged version proteins are shown. (C) Inhibition of translation elongation in a strain altered in ribosomal protein L28 does not affect P-bodies. Cells were grown in YPGlu, the culture was divided into two samples; cycloheximide at a concentration of $2 \mu \mathrm{g} / \mathrm{mL}$ for $10 \mathrm{~min}$ was added to one sample. The cells were washed in water with $(I I I, I V, V I I, V I I I)$ or without $(I, I I, V, V I)$ cycloheximide before they were collected and observed. 
when the cells were washed and resuspended in synthetic medium with glucose with, or without, cycloheximide (data not shown). Western analysis of the tagged proteins under these conditions indicated that the protein levels in each case remained constant (data not shown). Moreover, in yeast strains resistant to the effect of cycloheximide because of a point mutation in the ribosomal protein L28 (Stocklein and Piepersberg 1980), P-bodies were maintained in the presence of cycloheximide (Fig. 5C, IV, VIII). These observations suggest that cycloheximide is exerting its effect on P-bodies through inhibition of translation elongation. The simplest interpretation of these results is that the assembly of P-bodies requires nontranslating mRNA and when mRNAs are trapped in polysomes there is no significant residual P-body structure that remains. An implication of this model would be that P-bodies require RNA for their assembly. However, we cannot rule out the formal possibility that there is a, yet to be discovered, protein(s) that forms a P-body seed and remains in foci even when mRNAs are no longer available.

\section{P-bodies require RNA for assembly \\ P-bodies are sensitive to RNase A treatment}

The results above raised the possibility that $\mathrm{P}$-bodies require nontranslating mRNA for their assembly. In order to test whether P-bodies are dependent on RNA, we partially purified P-bodies from an $x r n 1 \Delta$ strain where they are abundant as compared to wild type (Sheth and Parker 2003). In this strain, P-bodies can be highly concentrated and purified by differential centrifugation such that a pellet is obtained that is enriched for P-bodies. Evidence that the pellet fraction contains P-bodies is microscopic identification of fluorescent foci similar to those observed in cells expressing Dcp2p-GFP (Fig. 6A). In addition, these foci increase in $x r n 1 \Delta$ as compared to wild-type cells (Fig. 6A, cf. I with II), contain multiple components of P-bodies, and decrease following cycloheximide treatment (M.A. Valencia-Sanchez and R. Parker, in prep.).

To determine if P-bodies require RNA for their integrity, we treated the enriched P-body fraction with RNase A and then repurified the P-bodies by centrifugation. Two assays indicated that RNase A treatment disrupted P-body integrity. First, re-examination of the pellet fraction following RNase A treatment showed a $>90 \%$ reduction in the number of microscopically identifiable P-bodies as assessed by Dcp2p, Dhh1p, or Lsm1p (Fig. 6B, IV-VI). Second, analysis of P-body components by Western analysis showed that P-body components that are initially in the pellet are now found in the supernatant following RNase A treatment (Fig. 6C; data not shown). Thus, these partially purified P-bodies are dependent on RNA for their integrity. Although these experiments were done with partially purified P-bodies from an $x r n 1 \Delta$ strain, similar results are seen with P-bodies
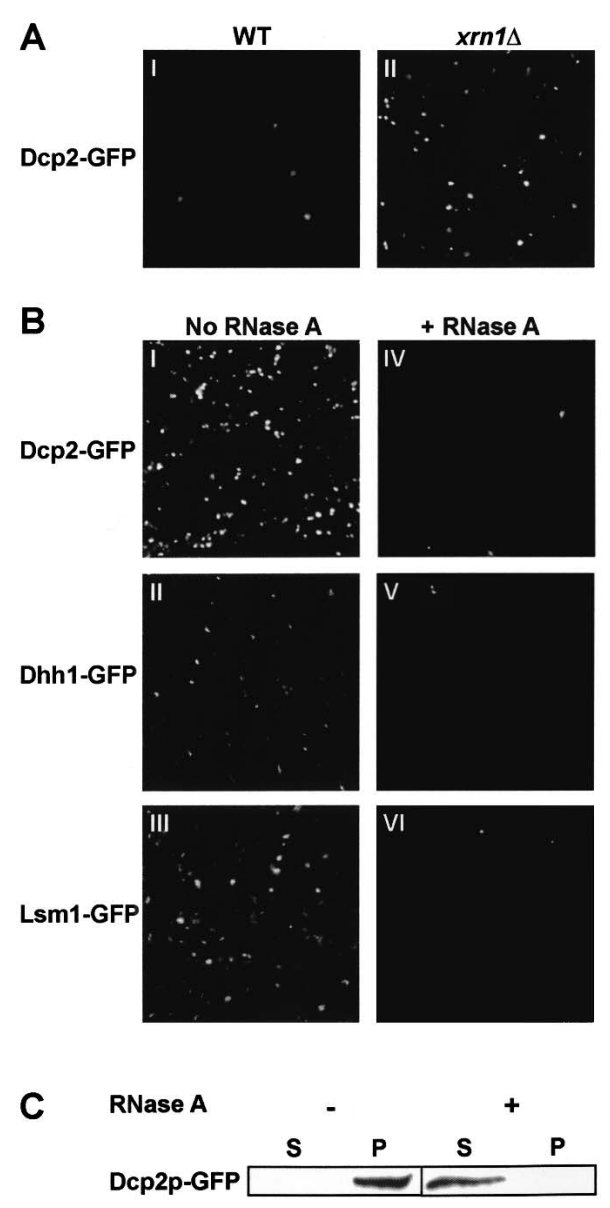

FIGURE 6. P-bodies are sensitive to RNase A digestion. (A) Microscopic analysis of P-body concentrated pellet from a $(I)$ wild-type (yRP1727) and an (II) xrn1s (yRP1923) strain expressing a GFPtagged version of Dcp2p. (B) Fluorescence microscopy of the P-body concentrated fractions in the presence $(I V-V I)$ and absence $(I-I I I)$ of RNase A. Dcp2p (yRP1923), Dhh1p (yRP1738), Lsm1p (yRP1924) GFP-tagged version proteins in $x r n 1 \Delta$ strain. $(C)$ Western blot analysis of the supernatant $(\mathrm{S})$ and pellet $(\mathrm{P})$ fractions from a Dcp2p-GFP $x r n 1 \Delta$ (yRP1923) strain in the presence $(+)$ or absence $(-)$ of RNase A.

purified from wild-type strains (data not shown). In addition, previous experiments indicate that the coimmunoprecipitation of different P-body components requires RNA (Tharun and Parker 2001). We interpret these observations to suggest that P-body proteins interact with mRNAs and then the resulting mRNPs aggregate into a larger structure. However, from this experiment we cannot formally distinguish what RNA is required for aggregation of the P-body structure, although the results presented below suggest it is mRNA.

\section{Increasing the level of trapped mRNA decay intermediates} increases P-body size

The work above suggested that the formation and integrity of P-bodies requires RNA. A prediction of this hypothesis is that if we trapped mRNAs in the process of degradation we 
should observe an increase in P-bodies. To test this prediction, we expressed high levels of an mRNA that produces an RNA fragment trapped in the process of degradation because of a strong secondary structure that blocks the $5^{\prime}$-to$3^{\prime}$ exonuclease Xrn1p (Decker and Parker 1993). In this experiment, we localized Dcp2p, as well as Dhh1p, in a strain containing a high-copy-number plasmid expressing the MFA2 mRNA with, or without, a poly $(\mathrm{G})$ tract in its 3'-UTR from the very strong glyceraldehyde-3-phosphate dehydrogenase $(G P D)$ gene promoter.

Cells containing high levels of MFA2 decay intermediate (Fig. 7A, V, VI) accumulated P-bodies. In contrast, cells void of plasmid (Fig. 7A, I, II), or expressing MFA2 mRNA without a functional poly $(\mathrm{G})$ tract, did not show an increase in P-body size (Fig. 7A, III, IV). This result indicates that the size and number of P-bodies can be increased by trapping mRNA in decay and is consistent with P-bodies requiring mRNAs for their formation.

We repeated this experiment using a different methodology. In this case, we compared yeast strains that expressed two reporter mRNAs (PGK1 and MFA2) with poly $(\mathrm{G})$ tracts in their $3^{\prime}$-UTRs under the control of a galactose-inducible promoter. Here we examined the appearance of P-bodies after transcription of these genes, and thus the accumulation of the decay intermediate, was induced by the presence of galactose in the growth medium. We observed that in the presence of galactose P-bodies were increased above those seen in glucose (Fig. 7B, cf. V-VI to VII-VIII). Moreover, yeast strains expressing mRNAs without the poly $(\mathrm{G})$ did not show a significant increase in P-bodies when grown on galactose media (Fig. 7B, III, IV). This indicates that the effect on P-body size is attributable to the accumulation of the poly $(G)$ mRNAs and not the change in carbon source.

We interpret these results to indicate that when mRNAs are trapped in the process of decay, P-bodies accumulate, which provides additional evidence that P-body formation is dependent on mRNA molecules. This result is also consistent with the observations that blocking decapping or $5^{\prime}$-to-3' degradation, which traps numerous mRNAs in the process of decay, leads to an increase in P-body size and number (Sheth and Parker 2003).

\section{mRNA localizes to P-bodies during translation repression}

The results above suggest that P-bodies form on nontranslating mRNAs. One prediction of this model is that specific mRNAs should be detectable in P-bodies during translation repression. To test this prediction, we localized the PGK1 mRNA within cells using a transcript containing multiple binding sites in its $3^{\prime}$-UTR for a U1A-GFP fusion protein (Brodsky and Silver 2000). This mRNA was distributed throughout the cytoplasm during cell growth in glucose (Fig. 8A). However, after $10 \mathrm{~min}$ of glucose deprivation, strains coexpressing the PGK1 mRNA containing U1Abinding sites and the U1A-GFP fusion protein showed a clear concentration of the GFP signal in cytoplasmic foci, which colocalized with Dcp2p (Fig. 8B-D). Control strains expressing the U1A-GFP without the target PGK1 mRNA did not show any concentration of the GFP signal in response to glucose deprivation (Fig. 8F). This provides direct evidence that mRNA molecules can be detected in P-bodies during translation repression.

\section{Translation factors are not associated with P-bodies}

The results above led to the hypothesis that P-bodies contain pools of nontranslating mRNPs. In order to examine the relationship between translation and P-bodies, we determined the subcellular distribution of translation factors. To this end, we used tagged genes for several translation factors with GFP in their chromosomal location under the
A
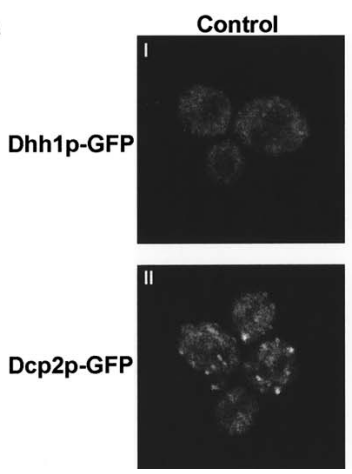

MFA2
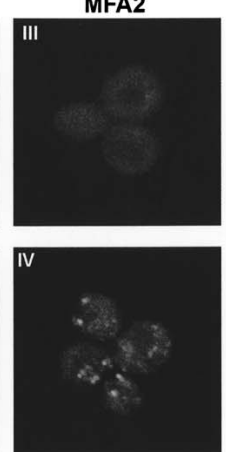
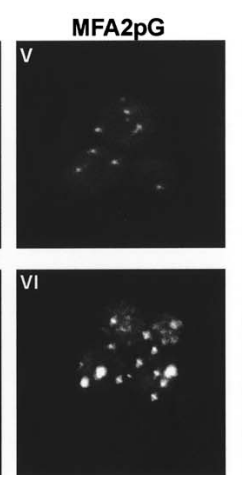

B
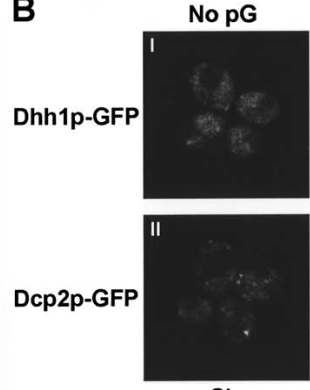

Glu
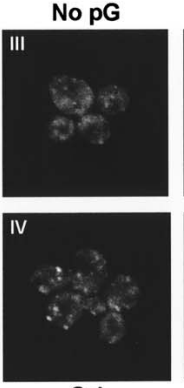

Gal
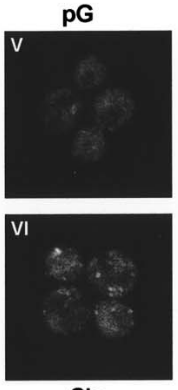

Glu

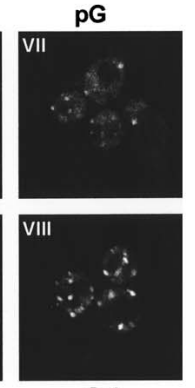

Gal

FIGURE 7. P-body integrity is dependent on mRNA. (A) Dhh1p GFP-tagged strain (yRP1724) and Dcp2p GFP-tagged strain (yRP1727) cells transformed with $(I I I, I V)$ pRP1083 [expressing MFA2 mRNA with no functional poly $(\mathrm{G})$ site] or $(V, V I)$ pRP1081 [expressing the MFA2 mRNA with poly $(\mathrm{G})$ ]; (I,II) control cells. Cells expressing a GFP-tagged version of (top panel) Dhh1p (yRP1824) and (bottom panel) Dcp2p (yRP1825). (B) Cells lacking the GAL-PGK1-pG/MFA2-pG constructs (I-IV) and expressing a GFP-tagged version of (top panel) Dhh1p (yRP1824) and (bottom panel) Dcp2p (yRP1825) grown in the presence of Glu (I,II) or Gal (III,IV). Cells expressing a GFP-tagged version of (top panel) Dhh1p (yRP1724) and (bottom panel) Dcp2p (yRP1727), containing the PGK1-pG/MFA2-pG constructs (V-VIII) grown in the presence of Glu (V,VI) or Gal (VII,VIII). 


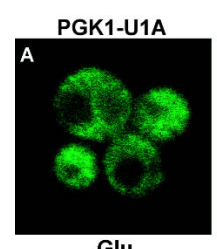

Glu
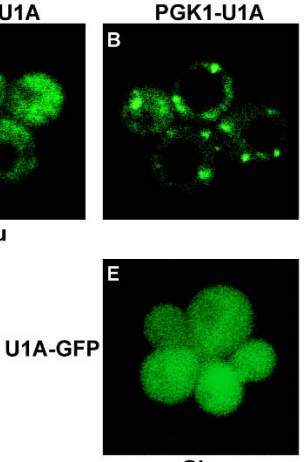

Glu

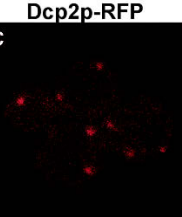

No Glu

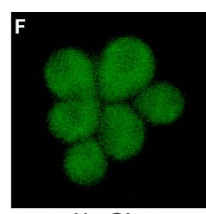

No Glu

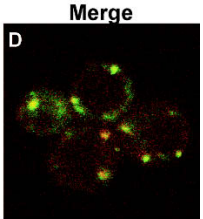

No glu
FIGURE 8. mRNA localizes to P-bodies during translation repression. Yeast strain yRP684 coexpressing $(A-C)$ U1A-GFP (pRP1187), PGK1-U1A (pPS2037), and Dcp2p-RFP (pRP1155), or (E,F) control U1A-GFP (pRP1187), was grown in SC plus Glu. For glucose depletion, cells were washed and resuspended in SC for $10 \mathrm{~min}$ before collection. For observation, cells were washed and resuspended in SC with $(A, E)$ or without $(B, C, F)$ Glu. $(D)$ Merged view.

control of their own promoter. The proteins examined include the translation initiation factor Prtlp, a subunit of the eIF3 translation initiation complex; TEF4p, a translation elongation factor; Sup45p, a translation termination factor; and RpL5p, a subunit of the large ribosomal subunit. We observed that these translation factors were distributed in the cell without any concentration in cytoplasmic foci during $\log$ growth (Fig. 9A, II; Fig. 9B, I-III). Moreover, we did not observe localization of these translation factors to Pbodies under glucose deprivation (Fig. 9A, V; Fig. 9B, IV$\mathrm{VI})$, conditions where P-bodies are dramatically increased (Fig. 2). Examination of RFP-tagged Dcp2p in the same cells showed that P-bodies were forming efficiently in these experiments (Fig. 9A, IV). We interpret these results to indicate that ribosomes, and multiple translation factors, do not accumulate in P-bodies. This supports the argument that mRNAs within P-bodies are in a nontranslating state.

\section{DISCUSSION}

\section{P-bodies require RNA for their assembly}

Two types of observations indicate that the formation of P-bodies requires RNA. First, trapping mRNA in the process of decay in vivo by cis-acting structures leads to the accumulation of P-bodies (Fig. 7). This result is consistent with the observation that inactivation of the decapping enzyme or 5'-to-3' exonuclease increases P-bodies in vivo (Sheth and Parker 2003). Second, semipurified P-bodies are sensitive to RNase A treatment as assessed both by microscopic and biochemical analysis (Fig. 6). This is also consistent with previous results that coimmunoprecipitation of P-body components is sensitive to RNase A treatment (Tharun and Parker 2001). Based on these observations, we conclude that the formation, or integrity, of P-bodies requires RNA.

Several observations support the argument that nontranslating mRNAs are the RNA underlying P-body formation. First, trapping mRNA molecules in the process of decay by the insertion of a poly $(\mathrm{G})$ tract in cis (Fig. 7) leads to increases in P-body formation. An important point is that mRNA fragments trapped by the insertion of poly $(\mathrm{G})$ tracts are not translated (Muhlrad et al. 1995), and are not found associated with ribosomes (Hilleren and Parker 2001). Second, driving yeast mRNAs into polysomes by
A
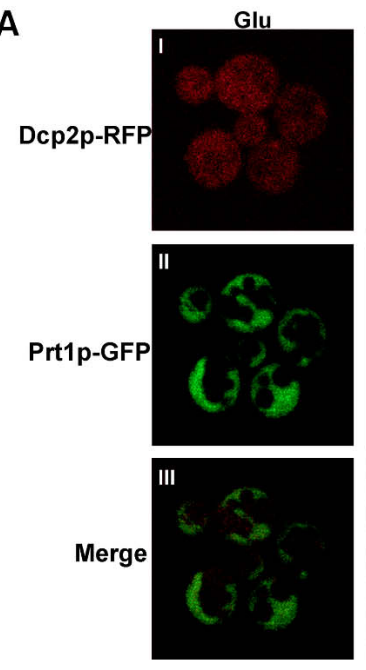

B
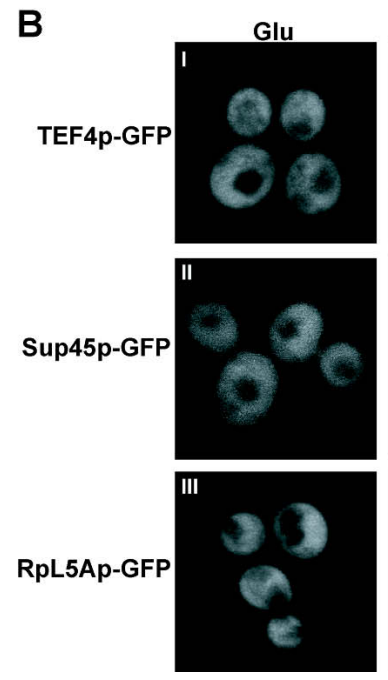
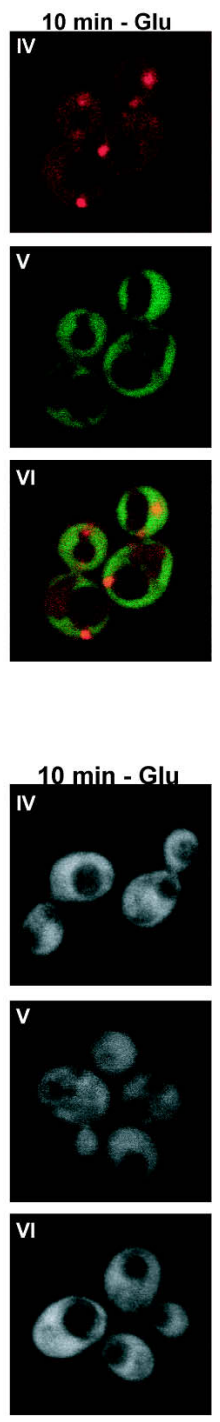

FIGURE 9. Translation factors are not associated with P-bodies. $(A)$ Cells were grown in SC plus Glu. For glucose depletion, cells were washed in SC for $10 \mathrm{~min}$ before collection. For observation, cells were washed and resuspended in SC with $(I, I I)$ or without $(I V-V)$ Glu. Cells coexpressing $(I, I I, I V, V)$ a GFP-tagged version of Prt1p (yRP1828) and an RFP-tagged version of Dcp2p (pRP1186). (III,VI) Merged views. (B) GFP-tagged versions of TEF4 (yRP1829), Sup45p (yRP1830), and RpL5p (yRP1911) were grown in YPGlu and observed as described in Figure 2A. Cells observed in the $(I-I I I)$ presence or $(I V-V I)$ absence of Glu are shown. 
inhibiting translation elongation leads to loss of P-bodies (Fig. 5; Sheth and Parker 2003; Kshirsagar and Parker 2004). Third, inhibition of translation initiation by mutations (Fig. 5) or cellular stresses leads to increases in Pbodies (Figs. 1-4). Fourth, translation factors and ribosome components are not found within P-bodies, even under conditions in which the P-bodies are large (Fig. 9). Fifth, PGK1 mRNA can be detected within P-bodies during glucose deprivation (Fig. 8). While we cannot formally rule out that there is an additional non-mRNA component of Pbodies, the pool of nontranslating mRNA can clearly affect the size and abundance of P-bodies.

The conclusion that P-bodies are dependent on mRNA for their formation implies that individual mRNPs have the ability to aggregate together, or that mRNAs can be specifically targeted to P-bodies. Such aggregation could occur through the interaction of mRNA-binding proteins that have multiple RNA-binding domains, and thereby provide links between individual mRNAs causing aggregation. Alternatively, there may be key RNA-binding proteins that, after binding to the mRNA, have the ability to interact with each other, thereby bringing the mRNPs together. This latter model is particularly appealing since the formation of nontranslating mRNAs into stress granules in mammalian cells appears to be dependent on a possible protein aggregation domain found in the mRNA-binding proteins TIA and TIA-R (Kedersha et al. 2000; Gilks et al. 2004).

An unresolved issue is whether P-bodies can form de novo. For example, there could be a pre-existing structure to which mRNAs and their associated proteins are targeted. Alternatively, mRNAs might form a specific type of mRNP that has the ability to aggregate into higher-order structures, which are then visualized in the light microscope as $\mathrm{P}$ bodies. Our results are most consistent with the latter possibility since all known components of P-bodies disperse when cycloheximide is introduced (Fig. 5). In addition, Pbodies appear to be able to form de novo when cells are subject to stresses, and are found throughout the cytoplasm. Based on these observations, the simplest model is that P-bodies form by the assembly of a specific mRNP structure on nontranslating mRNAs, which then has the ability to aggregate into larger structures.

\section{P-bodies may function in stress responses}

Our results suggest the possibility that P-bodies will be important in cellular responses to stress. The critical observation is that the size and number of P-bodies increased in several stress conditions including glucose deprivation, osmotic stress, ultraviolet light, and late stage of growth (Figs. 1-4). The cellular changes taking place during the stress conditions analyzed suggests a correlation between a decrease in translation rates and an increase in the concentration of P-bodies components in cytoplasmic foci. For example, glucose deprivation and osmotic stress are known to inhibit translation initiation and both lead to dramatic increases in P-bodies (Ashe et al. 2000; Uesono and Toh-e 2002; Uesono et al. 2004). In contrast, exposure of yeast cells to heat stress or oxidative stress does not seem to have an effect on translation rates (Uesono and Toh-e 2002; data not shown) and does not increase P-bodies (data not shown). We interpret these results to suggest that stresses that lead to decreases in translation initiation lead to an increase in P-bodies due to the movement of mRNAs from the translating, or polysome pool, to P-bodies.

The ability to sequester mRNAs into a nontranslating pool during stress conditions could be beneficial to the cell for three reasons. First, by sequestering the pre-stress pool of mRNAs into a nontranslating state, new mRNAs might be preferentially translated because of reduced competition from the pre-existing mRNAs. Second, if the mRNAs targeted to P-bodies during stress were also subsequently degraded, their targeting to P-bodies would assist in the reprogramming of the mRNA pool to reflect the new growth conditions. Third, if mRNAs targeted to P-bodies can return to the translating pool, then this system provides a way to transiently arrest translation on a subset of the mRNA population, and then to reuse such mRNAs when the cell has recovered from the stress conditions. This dynamic would be similar to what has been proposed for stress granules, which are particles of nontranslating mRNAs that form in response to stress (for review, see Anderson and Kedersha 2002). Stress granules have been proposed to play a role in storing mRNAs because stress granules decline during stress recovery, although whether this is caused by retranslation or degradation of the mRNA within the stress granule is not yet clear. Although mRNAs have not been demonstrated to re-enter translation following storage in P-bodies, this possibility is suggested by similarities between P-bodies and the storage and subsequent use of maternal mRNAs (Coller and Parker 2004).

An unresolved issue is the relationship between stress granules and P-bodies. To date, we have been unable to visualize stress granules in Saccharomyces cereviseae under a variety of conditions (data not shown), although they can be detected in Saccharomyces pombe (Dunand-Sauthier et al. 2002). However, several observations in mammalian cells suggest that P-bodies and stress granules are distinct structures. First, stress granules are generally only observed during a stress response, while P-bodies are present continually (Kedersha et al. 1999; Cougot et al. 2004). Second, at least at the current time, there appears to be different proteins present in these two structures. Stress granules contain translation initiation factors, small ribosomal subunits, and the mRNA-binding proteins TIA and TIA-R (Kedersha et al. 2002), whereas P-bodies contain mRNA decay factors (Ingelfinger et al. 2002; Lykke-Andersen 2002; van Dijk et al. 2002; Cougot et al. 2004). Third, direct visualization of these P-bodies and stress granules shows they are physically distinct and spatially separate (Cougot et al. 2004). How- 
ever, given that P-bodies and stress granules both contain nontranslating mRNAs and increase in response to stress, one anticipates that there may be some functional or temporal relationship between these pools of mRNPs.

\section{Movement of mRNA from translation to P-bodies}

Our results argue that movement of mRNAs from the polysome pool to P-bodies is an important and dramatic transition in the state of eukaryotic mRNA. This suggestion is based on P-bodies containing pools of nontranslating mRNAs and the reciprocal nature of the relationship between translation and P-bodies. A critical transition between a translating pool of mRNA and nontranslating mRNAs destined for degradation is also supported by coimmunoprecipitation experiments wherein decapping factors coimmunoprecipitated mRNAs but not translation factors (Tharun and Parker 2001). The movement of mRNAs from polysomes to P-bodies is striking in that it involves the loss of ribosomes and translation factors from the mRNA, the addition of mRNA decapping factors and proteins that promote P-body assembly, as well as physical movement of the mRNA between the polysome and P-body compartments. Interestingly, the composition of stress granules sug- gests stress granules might represent an intermediate state of mRNPs between translating mRNPs and mRNPs within P-bodies. Given that these transitions are likely to be sites of biological regulation, an important area of future work will be in determining the signals and mechanisms by which mRNA exit translation and enter the P-body compartment.

\section{MATERIALS AND METHODS}

\section{Yeast strains and growth conditions}

The genotypes of all strains used in this study are listed in Table 1 . All strains have GAL1 upstream activating sequence-regulated $P G K 1 p G$ and MFA2pG genes, as well as the LEU2 gene, collectively termed LEU2pm, integrated at the CUP1 locus unless stated otherwise (Hatfield et al. 1996). Proteins were C-terminal tagged with GFP following the PCR-based gene modification method described by Longtine et al. (1998). These fusion proteins include the full-length protein and are functional (Sheth and Parker 2003). Yeast crosses were carried out using standard laboratory procedures. Strains were grown on either standard yeast extract/peptone medium (YP) or synthetic medium (SC) yeast nitrogen base/ammonium sulfate supplemented with appropriate amino acids, and $2 \%$ dextrose $(\mathrm{Glu})$ or $2 \%$ galactose $(\mathrm{Gal})$ as carbon source, as indicated. Strains were grown at $30^{\circ} \mathrm{C}$ except for temperaturesensitive (ts) mutants, which were grown at $23^{\circ} \mathrm{C}$.

TABLE 1. Yeast strains

\begin{tabular}{|c|c|c|}
\hline Strain & Genotype & Source \\
\hline yRP684 & MATa leu2-3,112 trpl ura3-52 his4-539 lys2-201 & Hatfield et al. 1996 \\
\hline yRP840 & MATa leu2-3,112 trp1 ura3-52 his4-539 cup1::LEU2/PGK1pG/MFA2pG & Hatfield et al. 1996 \\
\hline yRP1724 & MATa leu2-3,112 trp1 ura3-52 his4-539 cup1::LEU2/PGK1pG/MFA2pG DHH1-GFP (NEO) & Sheth and Parker 2003 \\
\hline yRP1726 & MATa leu2-3,112 trp1 ura3-52 his4-539 cup1::LEU2/PGK1pG/MFA2pG DCP1-GFP (NEO) & Sheth and Parker 2003 \\
\hline yRP1727 & MATa leu2-3,112 trp1 ura3-52 his4-539 cup1::LEU2/PGK1pG/MFA2pG DCP2-GFP (NEO) & Sheth and Parker 2003 \\
\hline yRP1728 & MATa leu2-3,112 trp1 ura3-52 his4-539 cup1::LEU2/PGK1pG/MFA2pG PAT1-GFP (NEO) & Sheth and Parker 2003 \\
\hline yRP1729 & MATa leu2-3,112 trp1 ura3-52 his4-539 cup1::LEU2/PGK1pG/MFA2pG LSM1-GFP (NEO) & Sheth and Parker 2003 \\
\hline yRP1730 & MATa leu2-3,112 trp1 ura3-52 his4-539 cup1::LEU2/PGK1pG/MFA2pG XRN1-GFP (NEO) & Sheth and Parker 2003 \\
\hline yRP1738 & $\begin{array}{l}\text { MATa leu2-3,112 trp1 ura3-52 his4-539 cup1::LEU2/PGK1pG/MFA2pG xrn1::TRP DHH1- } \\
\text { GFP (NEO) }\end{array}$ & Sheth and Parker 2003 \\
\hline yRP1824 & MATa leu2-3,112 trp1 ura3-52 his4-539 DHH1-GFP (NEO) & This study \\
\hline yRP1825 & 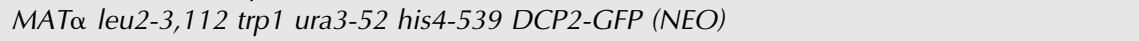 & This study \\
\hline yRP1826 & $\begin{array}{l}\text { MATa leu2-3,112 trp1 ura3-52 his4-539 prt1-63 cup1::LEU2/PGK1pG/MFA2pG DHH1-GFP } \\
\text { (NEO) }\end{array}$ & This study \\
\hline yRP1827 & MATa leu2-3,112 ura3-52 prt1-63 cup1::LEU2/PGK1pG/MFA2pG DCP2-GFP (NEO) & This study \\
\hline yRP1828 & MATa leu2 ura3 his3 met15 PRT1-GFP (HIS) & Huh et al. 2003 \\
\hline yRP1829 & MATa leu2 ura3 his3 met15 TEF4-GFP (HIS) & Huh et al. 2003 \\
\hline yRP1830 & MATa leu2 ura3 his3 met15 SUP45-GFP (HIS) & Huh et al. 2003 \\
\hline yRP1911 & MATa leu2 ura3 his3 met15 RPL5-GFP (HIS) & Huh et al. 2003 \\
\hline yRP1912 & $\begin{array}{l}\text { MATa leu2-3,112 trp1 ura3-52 cup1::LEU2/PGK1pG/MFA2pG hog1::NEO DHH1-GFP } \\
\text { (NEO) }\end{array}$ & This study \\
\hline yRP1913 & $\begin{array}{l}\text { MATa leu2-3,112 trp1 ura3-52 his4-539 cup1::LEU2/PGK1pG/MFA2pG hog1::NEO DCP2- } \\
\text { GFP (NEO) }\end{array}$ & This study \\
\hline yRP1921 & MATa leu2-3,112 trp1 his4-539 met1 cyh2 DHH1-GFP (NEO) & This study \\
\hline yRP1922 & MATa leu2-3,112 trp1 ura3-52 his4-539 cyh2 DCP2-GFP (NEO) & This study \\
\hline yRP1923 & $\begin{array}{l}\text { MATa leu2-3,112 trp1 ura3-52 his4-539 cup1::LEU2/PGK1pG/MFA2pG xrn1::TRP DCP2- } \\
\text { GFP (NEO) }\end{array}$ & This study \\
\hline yRP1924 & $\begin{array}{l}\text { MATa leu2-3,112 trp1 his4-539 cup1::LEU2/PGK1pG/MFA2PpG xrn1::TRP LSM1-GFP } \\
\text { (NEO) }\end{array}$ & This study \\
\hline
\end{tabular}




\section{Plasmids}

Plasmid pRP1081, expressing the MFA2 mRNA with a poly $(G)$ tract, or pRP1083, expressing MFA2 mRNA with no functional poly $(\mathrm{G})$ tract, were constructed as described in Sheth and Parker (2003). The plasmid DCP2-RFP, pRP1186, was created by PCRamplification of the DCP2 gene from yRP840, and the fragment was ligated into the yeast expression vector pRP1084 between the SalI and BamHI sites (Sheth and Parker 2003) and confirmed by sequencing. For PGK1 mRNA localization, the plasmid U1A-GFP, pRP1187, was created by replacement of the GAL promoter, in plasmid pPS2042 (Brodsky and Silver 2000), with the GPD promoter in between SalI sites. A plasmid expressing PGK1 with U1A-binding sites (pPS2037) was created as described in Brodsky and Silver (2000). The CEN LEU plasmid, pRP1155 (U. Sheth and R. Parker, in prep.), expressing DCP2-RFP derives from pRP1186. Yeast strains were transformed by standard techniques, and plasmids were maintained by growth in selective media.

\section{UV stress treatment}

Cells carrying GFP-tagged proteins were grown in YPGlu to log phase. Then $1 \mathrm{~mL}$ of cells was surface-spread in duplicate into YPGlu plates and air-dried. One plate was treated with $50 \mu \mathrm{J}$ of UV light, and the other plate was used as a control without exposure to UV light. Cells were resuspended in YPGlu and continued to grow. Samples were collected 15, 30, and $45 \mathrm{~min}$ after UV light treatment. For the no UV light control, cells were resuspended from the plate not exposed to UV light in YPGlu and grown as described above, and samples were collected after $45 \mathrm{~min}$. Samples were analyzed as described below.

\section{Preparation of cells for confocal microscopy}

The cells were grown to an $\mathrm{OD}_{600}$ of $0.3-0.35$ in the appropriate medium. Cells were washed two times with SC plus amino acids supplemented with the same carbon source used for cell growth. Cells were resuspended in SC containing the appropriate carbon source and amino acids and immediately observed, unless otherwise indicated. Observations were made using a Nikon PCM 2000 Confocal Microscope using a $100 \times$ objective with $3 \times$ zoom with Compix Software. All images are a Z-series compilation of 6-10 images in a stack, except for colocalization analysis, where images result from a single $\mathrm{Z}$-section.

\section{Preparation of semipurified P-bodies}

For P-bodies, $250 \mathrm{~mL}$ of cells was grown to an $\mathrm{OD}_{600}$ of 3 , harvested by centrifugation, and washed in cold lysis buffer $(50 \mathrm{mM}$ Tris at $\mathrm{pH} 7.6,50 \mathrm{mM} \mathrm{NaCl}, 5 \mathrm{mM} \mathrm{MgCl}_{2}, 0.1 \% \mathrm{NP}-40,1 \mathrm{mM}$ $\beta$-mercaptoethanol, $1 \times$ protease inhibitor complete mini EDTA free [Roche, \#1836170], 0.4 U/ $\mu \mathrm{L}$ RNase inhibitor). All subsequent steps were performed at $4^{\circ} \mathrm{C}$. Cells were lysed by vortexing in the presence of cold lysis buffer and an equal volume of glass beads. Lysates were clarified briefly at $2000 \mathrm{~g}$ for $2 \mathrm{~min}$. The supernatant was centrifuged at $10,000 \mathrm{~g}$ for $10 \mathrm{~min}$, and a P-body pellet was formed. Most of the supernatant was removed, and the pellet was resuspended in lysis buffer without RNase inhibitor. The resuspended pellet was then split into two equal portions. One portion was treated with RNase A to a concentration of $1 \mu \mathrm{g} / \mu \mathrm{L}$ for $30 \mathrm{~min}$ at room temperature. The other portion was incubated under the same conditions with cold lysis buffer. After incubation, both RNase A treated and untreated fractions were centrifuged at $10,000 \mathrm{~g}$ for $10 \mathrm{~min}$, producing the final supernatant and pellet. For microscopic analysis, $10 \mu \mathrm{L}$ of the P-body rich pellet was visualized directly with the confocal microscope. For Western blot analysis, equal volumes of the pellet and supernatant fractions for control and sample were used. Western blot analysis of the GFP-tagged proteins was carried out following standard protocols using GFP primary antibody (Covance) at a 1:1000 dilution and goat antimouse HRP secondary antibody (Sigma-Aldrich) at a 1:5000 dilution.

\section{ACKNOWLEDGMENTS}

We thank the members of the Parker lab for helpful discussions, especially Kristian Baker, Carolyn Decker, Anne Webb, Bettsy Garcia-Montijo, Jeffery Coller, Debrah Thompson, and Meenakshi Kshirsagar for critical reading of the manuscript. We also thank the Department of Molecular \& Cellular Biology for the use of the confocal facility. NIH grant (R37 GM45443) and funds from the Howard Hughes Medical Institute supported this work. D.T. was supported by Fundacao para a Ciencia e Tecnologia (SFRH/BD/ 2739/2000), Portugal.

Received November 17, 2004; accepted December 10, 2004.

\section{REFERENCES}

Anderson, P. and Kedersha, N. 2002. Stressful initiations. J. Cell Sci. 115: 3227-3234.

Ashe, M.P., De Long, S.K., and Sachs, A.B. 2000. Glucose depletion rapidly inhibits translation initiation in yeast. Mol. Biol. Cell 3: 833-848.

Bashkirov, V.I., Scherthan, H., Solinger, J.A., Buerstedde, J.M., and Heyer, W.D. 1997. A mouse cytoplasmic exoribonuclease (mXRN1p) with preference for G4 tetraplex substrates. J. Cell Biol. 136: 761-773.

Beelman, C.A. and Parker, R. 1994. Differential effects of translational inhibition in cis and in trans on the decay of the unstable yeast MFA2 mRNA. J. Biol. Chem. 13: 9687-9692.

Birrell, G.W., Giaever, G., Chu, A.M., Davis, R.W., and Brown, J.M. 2001. A genome-wide screen in Saccharomyces cerevisiae for genes affecting UV radiation sensitivity. Proc. Natl. Acad. Sci. 98: 1260812613.

Brodsky, A.S. and Silver, P.A. 2000. Pre-mRNA processing factors are required for nuclear export. RNA 6: 1737-1749.

Coller, J. and Parker, R. 2004. Eukaryotic mRNA decapping. Ann. Rev. Biochem. 73: 861-890.

Coller, J.M., Tucker, M., Sheth, U., Valencia-Sanchez, M.A., and Parker, R. 2001. The DEAD box helicase, Dhhlp, functions in mRNA decapping and interacts with both the decapping and deadenylase complexes. RNA 7: 1717-1727.

Cougot, N., Babajko, S., and Seraphin, B. 2004. Cytoplasmic foci are sites of mRNA decay in human cells. J. Cell Biol. 165: 31-40.

Decker, C.J. and Parker, R. 1993. A turnover pathway for both stable and unstable mRNAs in yeast: Evidence for a requirement for deadenylation. Genes \& Dev. 7: 1632-1643.

de Nadal, E., Alepuz, P.M., and Posas, F. 2002. Dealing with osmostress through MAP kinase activation. EMBO Rep. 8: 735-740.

Dunand-Sauthier, I., Walker, C., Wilkinson, C., Gordon, C., Crane, R., Norbury, C., and Humphrey, T. 2002. Sum1, a component of 
the fission yeast eIF3 translation initiation complex, is rapidly relocalized during environmental stress and interacts with components of the 26S proteasome. Mol. Biol. Cell 13: 1626-1640.

Evans, D.R., Rasmussen, C., Hanic-Joyce, P.J., Johnston, G.C., Singer, R.A., and Barnes, C.A. 1995. Mutational analysis of the Prt1 protein subunit of yeast translation initiation factor 3. Mol. Cell. Biol. 15: $4525-4535$.

Fischer, N. and Weis, K. 2002. The DEAD box protein Dhh1 stimulates the decapping enzyme Dcp1. EMBO J. 21: 2788-2797.

Gilks, N., Kedersha, N., Ayodele, M., Shen, L., Stoecklin, G., Dember, L.M., and Anderson, P. 2004. Stress granule assembly is mediated by prion-like aggregation of TIA-1. Mol. Biol. Cell 15: 5388-5398.

Hatfield, L., Beelman, C.A., Stevens, A., and Parker, R. 1996. Mutations in trans-acting factors affecting mRNA decapping in Saccharomyces cerevisiae. Mol. Cell. Biol. 16: 5830-5838.

Hilleren, P. and Parker, R. 2001. Defects in the mRNA export factors Rat7p, Glelp, Mex67p and Rat8p cause hyperadenylation during $3^{\prime}$ end formation of nascent transcripts. RNA 7: 753-764.

Hsu, C.L. and Stevens, A. 1993. Yeast cells lacking 5'-3' exoribonuclease 1 contain mRNA species that are poly(A) deficient and partially lack the $5^{\prime}$ cap structure. Mol. Cell. Biol. 13: 4826-4835.

Huh, W.K., Falvo, J.V., Gerke, L.C., Carroll, A.S., Howson, R.W., Weissman, J.S., and O'Shea, E.K. 2003. Global analysis of protein localization in budding yeast. Nature 425: 686-691.

Ingelfinger, D., Arndt-Jovin, D.J., Luhrmann, R., and Achsel, T. 2002. The human LSm1-7 proteins colocalize with the mRNA-degrading enzymes Dcp1/2 and Xrnl in distinct cytoplasmic foci. RNA 8: 1489-1501.

Jacobs, J.S., Anderson, A.R., and Parker, R. 1998. The 3' to 5' degradation of yeast mRNAs is a general mechanism for mRNA turnover that requires the SKI2 DEVH box protein and $3^{\prime}$ to $5^{\prime}$ exonucleases of the exosome complex. EMBO J. 17: 1497-1506.

Kedersha, N.L., Gupta, M., Li, W., Miller, I., and Anderson, P. 1999. RNA-binding proteins TIA-1 and TIAR link the phosphorylation of eIF- $2 \alpha$ to the assembly of mammalian stress granules. J. Cell Biol. 27: 1431-1442.

Kedersha, N., Cho, M.R., Li, W., Yacono, P.W., Chen, S., Gilks, N., Golan, D.E., and Anderson, P. 2000. Dynamic shuttling of TIA-1 accompanies the recruitment of mRNA to mammalian stress granules. J. Cell Biol. 151: 1257-1268.

Kedersha, N., Chen, S., Gilks, N., Li, W., Miller, I.J., Stahl, J., and Anderson, P. 2002. Evidence that ternary complex (eIF2-GTPtRNA $_{i}{ }^{\text {Met }}$-deficient preinitiation complexes are core constituents of mammalian stress granules. Mol. Biol. Cell 13: 195-210.

Khanna, R. and Kiledjian, M. 2004. Poly(A)-binding-protein-mediated regulation of hDcp2 decapping in vitro. EMBO J. 23: 19681976.

Kshirsagar, M. and Parker, R. 2004. Identification of Edc3p as an enhancer of mRNA decapping in Saccharomyces cerevisiae. Genetics 166: 729-739.

LaGrandeur, T. and Parker, R. 1999. The cis acting sequences responsible for the differential decay of the unstable MFA2 and stable PGK1 transcripts in yeast includes the context of the translational short codon. RNA 5: 420-433.

Longtine, M.S., Mckenzie, A., Demarini, D.J., Shah, N.G., Wach, A.,
Brachat, A., Philippsen, P., and Pringle, J.R. 1998. Additional modules for versatile and economical PCR-based gene deletion and modification in Saccharomyces cerevisiae. Yeast 14: 1-9.

Lykke-Andersen, J. 2002. Identification of a human decapping complex associated with hUpf proteins in nonsense-mediated decay. Mol. Cell. Biol. 22: 8114-8121.

Mitchell, P., Petfalski, E., Shevchenko, A., Mann, M., and Tollervey, D. 1997. The exosome: A conserved eukaryotic RNA processing complex containing multiple $3^{\prime} \rightarrow 5^{\prime}$ exoribonucleases. Cell 91: 457466.

Muckenthaler, M., Gunkel, N., Stripecke, R., and Hentze, M.W. 1997. Regulated poly(A) tail shortening in somatic cells mediated by cap-proximal translational repressor proteins and ribosome association. RNA 3: 983-995.

Muhlrad, D. and Parker, R. 1994. Premature translational termination triggers mRNA decapping. Nature 370: 578-581.

Muhlrad, D., Decker, C.J., and Parker, R. 1995. Turnover mechanisms of the stable yeast PGK1 mRNA. Mol. Cell. Biol. 15: 2145-2156.

Parker, R. and Song, H. 2004. The enzymes and control of eukaryotic mRNA turnover. Nat. Struct. Mol. Biol. 11: 121-127.

Peltz, S.W., Donahue, J.L., and Jacobson, A. 1992. A mutation in the tRNA nucleotidyltransferase gene promotes stabilization of mRNAs in Saccharomyces cerevisiae. Mol. Cell. Biol. 12: 5778-5784.

Ramirez, C.V., Vilela, C., Berthelot, K., and McCarthy, J.E. 2002. Modulation of eukaryotic mRNA stability via the cap-binding translation complex eIF4F. J. Mol. Biol. 318: 951-962.

Rolland, F., Winderickx, J., and Thevelein, J.M. 2002. Glucose-sensing and -signalling mechanisms in yeast. FEMS Yeast Res. 2: 183-201.

Schwartz, D. and Parker, R. 1999. Mutations in translation initiation factors lead to increased rates of deadenylation and decapping of yeast mRNAs. Mol. Cell. Biol. 19: 5247-5256.

- 2000. mRNA decapping in yeast requires dissociation of the cap binding protein, eukaryotic translation initiation factor $4 \mathrm{E}$. Mol. Cell. Biol. 20: 7933-7942.

Sheth, U. and Parker, R. 2003. Decapping and decay of messenger RNA occur in cytoplasmic processing bodies. Science 300: 805-808.

Stocklein, W. and Piepersberg, W. 1980. Altered ribosomal protein L29 in a cycloheximide-resistance strain in Saccharomyces cerevisiae. Curr. Genetics 1: 177-183.

Tharun, S. and Parker, R. 2001. Targeting an mRNA for decapping: Displacement of translation factors and association of the Lsmlp7p complex on deadenylated yeast mRNAs. Mol. Cell. 8: 10751083.

Uesono, Y. and Toh-e, A. 2002. Transient inhibition of translation initiation by osmotic stress. J. Biol. Chem. 16: 13848-13855.

Uesono, Y., Ashe, M.P., and Toh-e, A. 2004. Simultaneous yet independent regulation of actin cytoskeletal organization and translation initiation by glucose in Saccharomyces cerevisiae. Mol. Biol. Cell 4: 1544-1556.

van Dijk, E., Cougot, N., Meyer, S., Babajko, S., Wahle, E., and Seraphin, B. 2002. Human Dcp2: A catalytically active mRNA decapping enzyme located in specific cytoplasmic structures. $E M B O$ J. 21: 6915-6924.

van Hoof, A. and Parker, R. 1999. The exosome: A proteasome for RNA? Cell 99: 347-350. 

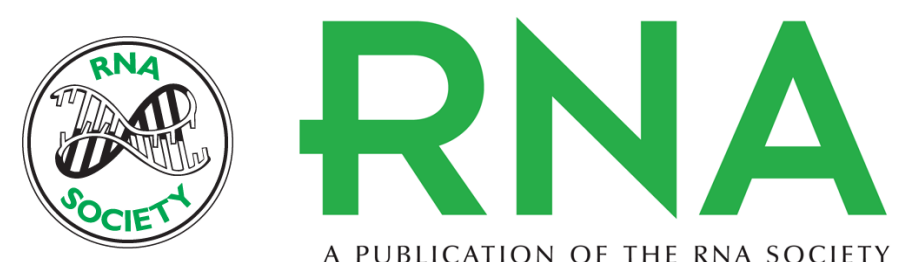

A PUBLICATION OF THE RNA SOCIETY

\section{Processing bodies require RNA for assembly and contain nontranslating mRNAs}

DANIELA TEIXEIRA, UJWAL SHETH, MARCO A. VALENCIA-SANCHEZ, et al.

RNA 2005 11: 371-382

References This article cites 42 articles, 27 of which can be accessed free at: http://rnajournal.cshlp.org/content/11/4/371.full.html\#ref-list-1

\section{License}

Email Alerting Receive free email alerts when new articles cite this article - sign up in the box at the Service top right corner of the article or click here. 